\title{
Consistent biodiversity effects across ecosystem functions
}

\author{
Seraina Cappelli ${ }^{1}$, Noémie Pichon ${ }^{1}$, Tosca Mannall ${ }^{1}$, and Eric Allan ${ }^{1}$ \\ ${ }^{1}$ University of Bern
}

May 18, 2020

\begin{abstract}
Biodiversity affects ecosystem functioning through complementarity effects, driven by many species, and selection effects, driven by few. Selection effects occur through interspecific abundance shifts (dominance) and intraspecific shifts in functioning. Complementarity and selection are often calculated for biomass, but we know little about how diversity affects other ecosystem functions. We calculated diversity effects for aboveground biomass, insect herbivory, pathogen infection and two leaf traits as nutrient cycling proxies, in a grassland experiment (PaNDiv) manipulating species richness, functional composition, nitrogen enrichment and fungicide treatment. Complementarity effects were always positive, showing that multiple species contribute to diversity effects. Intraspecific selection effects were always negative because species converged in their functioning in polyculture. Despite these overall consistencies, diversity effects for the five functions were not correlated, suggesting different species drive the different functions. These results show that different underlying mechanisms can result in similar overall diversity effects across functions.
\end{abstract}

\section{Hosted file}

20200514_Cappelli et al_submission to ecology letters.docx available at https://authorea.com/ users/323475/articles/452142-consistent-biodiversity-effects-across-ecosystem-functions 